\title{
BLAME AND THE HuMEAN THEORY OF MOTIVATION
}

$\sim$ Abstract $\sim$

A classic, though basically neglected question about motivation arises when we attempt to account for blame's nature-namely, does the recognition central to blame need help from an independent desire in order to motivate the blame-characteristic dispositions that arise in the blamer? Those who have attended to the question think the answer is yes. Hence, they adopt what I call a Humean Construal of blame on which blame is (a) a judgment that an individual $\mathrm{S}$ is blameworthy and (b) an independent desire about S not doing as they did or being as they are. This paper rejects arguments for the Humean Construal, illustrates deep failings of that view, and uses these considerations to support anti-Humean accounts of blame in particular and moral motivation more broadly.

$$
\sim \text { Keywords } \sim
$$

blame; Humean Theory of Motivation; Anti-Humean Theory of Motivation; reactive attitudes; P.F. Strawson;

\author{
Forthcoming, Philosophia
} Please cite the Published Version 


\section{Blame AND the HumEAN THEORY OF MOTIVATION}

Typically, when an individual recognizes an act as disrespectful or callous, they are moved to understand their relation to the actor differently or redress them for their disregard. For instance, suppose Simi's close friend, Gena, hinted at the truth of unfounded rumors of marital infidelity on Simi's behalf. Were Simi to recognize that Gena betrayed her confidence, we would expect it to stir her to see Gena in a new light, interact with Gena on new terms, and, perhaps, stand poised to rebuke her. Though difficult to characterize, this sort of recognition and the associated changes are taken to be at the heart of blame. Thus, a classic, though basically neglected, question about motivation arises when we attempt to account for blame's nature: Does the recognition central to blame need help from an independent desire in order to motivate the blamecharacteristic dispositions that arise in the blamer?

Some think it does, and, so, construe blame as a particular belief-desire pair (e.g. Sher (2006; 2013) and Capes (2010)). This, Humean Construal, as I'll call it, is at least prima facie attractive to those who antecedently accept the Humean Theory of Motivation (HTM). At the heart of HTM is the Humean idea that cognitive states like judgments are inert and need aid from independent desire to motivate. So, an agent's belief that she ought to save the child she sees drowning is insufficient for disposing her to action. What is needed, the Humean contends, is, e.g., a pre-existing desire to do what she believes she ought. Interestingly, only two proponents of the Humean Construal offer arguments in favor of extending HTM to capture the nature of blame. This paper rejects their arguments, illustrates deep failings of the Humean Construal, and uses these considerations to support anti-Humean models of blame and moral motivation. 
More precisely, according to the Humean Construal, blame is constitutively linked to a belief-desire pair that consists of (i) a belief that an individual, S, acted in a blameworthy manner, $\varphi$, and (ii) a desire that $\mathrm{S}$ not have $\varphi$-ed or (iii) a desire that $\mathrm{S}$ not be as they are. The idea is that this pair motivates, for example, the disposition to resent the one judged to have acted in a blameworthy manner. ${ }^{1}$ In support, Justin Capes (2010) focuses primarily on the dialectical gains of the Humean Construal. According to Capes, the Humean Construal clears the way for a better rejection of principles like the

Principle of Alternative Possibilities (PAP): $\quad$ An individual $\mathrm{S}$ is morally responsible for $\varphi$ only if $S$ could have done other than $\varphi$.

Alternatively, Sher (2006) argues that the Humean Construal is the only theory of blame's nature that adequately captures the most important aspects of the phenomenon.

Neither Capes's nor Sher's argument is successful. Capes's mistake does not speak directly to the viability of the Humean Construal, but Sher's does. Sher's argument turns on the claim that the Humean Construal does better than the widely held view about blame's nature inspired by P. F. Strawson—namely, the

Reactive Attitudes Account: Moral-responsibility responses (e.g. praise and blame) are constituted by a reactive attitude (i.e. a complex conative-affective attitude like resentment, indignation, guilt, gratitude, approbation, and pride) ${ }^{2}$

After rejecting Capes's argument, I point out that there is a nearby, plausible Strawsonoriented account of blame's nature that withstands Sher's criticism (§1). Furthermore,

\footnotetext{
${ }^{1}$ See, e.g., Sher (2006, Chpt. 6).

${ }^{2}$ Strawson (1962). There are many versions of this account but this will not effect my arguments here.
} 
the alternative Strawsonian account is anti-Humean insofar as it discards the Humean idea that cognitive states cannot motivate absent independent desire. To complete the argument against Sher and further push against incorporating the Humean idea into accounts of blame's nature, I show that doing so objectionably distorts the target phenomenon and, so, Strawsonian, anti-Humean alternatives are more plausible (§2).

Finally, I use these results to buttress support for versions of the Anti-Humean Theory of Motivation (§3). On that theory, our cognitive states are not essentially inert. So, an agent's judgment that she ought to save the child she sees drowning is (typically) sufficient for disposing her to action. The basic idea is that, if, when it comes to blame, we should reject the Humean idea as this essay argues we should, then we need states with cognitive and conative aspects for explanatory purposes. Hence, contrary to what some Humeans suspect, positing such states is not ad hoc. And, so long as these states are neither impossible nor incoherent, prominent resistance to anti-Humean theories of motivation is also undercut. I address each concern prior to concluding that we have good reason to be anti-Humean about blame and, hence, moral motivation as well. I turn, then, to see what's been said in favor of the Humean Construal and show why, in the end, it gives us no reason to adopt it as an account of blame's nature.

\section{1: $\quad$ Two ARguments For the Humean CONSTRuAL}

In this section, I show that two arguments for the Humean Construal fail. 


\section{1: $\quad$ The Humean Construal and the W-Defense}

In opposition to PAP (i.e. the Principle of Alternative Possibilities), many offer counterexamples known as Frankfurt-Type Cases (FTCs) which purport to show that someone can lack access to alternative courses of action and yet be morally responsible for what they do. ${ }^{3}$ A chief difficulty for employing FTCs against PAP is overcoming David Widerker's so-called, W-Defense. ${ }^{4}$ The W-Defense challenges proponents of the FTC-strategy to state what it is reasonable to expect the actor in their favorite FTC to do. The W-Defense presses that it is not reasonable to expect the actor in FTCs to do other than they have the power to do and, so, it is unreasonable to blame them for what they did. In Widerker's words:

...since you [...] wish to hold Jones blameworthy for [shooting Smith], tell me what, in your opinion, should [she] have done instead? Now you cannot claim that [she] should not [shoot Smith], since this was something that was not in [her] power to do. Hence, I do not see how you can hold [her] blameworthy for [shooting him]. (Widerker, 2003, 63, his emphasis)

Capes presents Widerker's argument in the following way:

The W-Defense's Core Argument ${ }^{5}$ :

W1) To hold $S$ blameworthy for $A$-ing essentially involves an expectation that $S$ not have $A$-ed.

W2) But to expect that $S$ not have $A$-ed would be unreasonable if $S$ could not have done otherwise than $A$.

\footnotetext{
${ }^{3}$ Named for Harry Frankfurt (1969). For excellent collections on this debate see, Widerker \& McKenna (2003) and Cuypers \& Moya (2009).

${ }^{4}$ Widereker (2003).

${ }^{5}$ Capes $(2010,73)$. Note that Capes's argument is limited in scope, since it only appeals to those who reject the W-Defense.
} 
W3) Hence, holding $S$ blameworthy for $A$-ing when $S$ could not have done otherwise than $A$ would involve an unreasonable expectation on the part of those holding $S$ blameworthy.

As Capes points out, many attempt to show that (W2) is false and thereby wade into the deep, dark ocean of the metaphysics of free will. ${ }^{6}$ To avoid those waters Capes rejects (W1) by adopting the Humean Construal which, on his view, does not involve an expectation that $\mathrm{S} \varphi$, but rather a desire that $\mathrm{S}$ not have done so.

To better understand Capes's argument, look more closely at how the W-Defense is used in an attempt to show that FTCs fail as counterexamples to PAP. FTCs involve a counterfactual intervener, Black, who is poised and able to make another person, Jones, do what he wants should he get a hint that she will decide to do otherwise. But, Jones does as Black wants. For instance, in some FTCs, for her own reasons Jones shoots Black's political nemesis, Smith. And, since Black wanted Jones to do that, he doesn't intervene. The idea is that, intuitively, Jones is blameworthy for shooting Smith despite the fact that Jones lacked access to alternative actions. Not persuaded, some employ Widerker's W-Defense to support their resistance. Widerker holds that blame of Jones is fitting only if the expectation that Jones refrain from shooting Smith was reasonable. And, in order for that expectation to be reasonable, Jones must have had the power to refrain from shooting Smith. Since the presence of Black is supposed to make it true that Jones does not have that power, the expectation in question is unreasonable. Thus, Widerker concludes, unless we are willing to give up the view that it is reasonable to

\footnotetext{
${ }^{6}$ For instance, rejecting (W2) often involves debating the nature of alternative possibilities, since many think that some alternatives are insufficient for action attribution or irrelevant to attributing something to an individual as the basis of moral appraisal. Capes (2010) discusses those sorts of debates at length.
} 
expect an agent to $\varphi$ only if she has the power to $\varphi$, we should reject the intuition that Jones is blameworthy.

As Capes sees it, from the Humean perspective the assumption that expectations are essential to blame is false. ${ }^{7}$ On his view, what is essential to blame is a certain belief and desire, e.g., the belief that $\mathrm{S}$ did something wrong and the desire that $\mathrm{S}$ not have done what she did. So, Capes thinks that we should replace

(W1) To hold $S$ blameworthy for $A$-ing essentially involves an expectation that $S$ not have $A$-ed,

with something like

(H1) To hold $S$ blameworthy for $A$-ing essentially involves (a) a belief that $S$ is blameworthy for $A$-ing, and (b) a desire that $S$ not have $A$-ed.

Since this move does not require taking a stand on deep metaphysical issues about things like the nature of alternative possibilities, Capes concludes that adopting the Humean Construal offers a superior response to the W-Defense.

The elegance of Capes's strategy notwithstanding, adopting the Humean Construal does not purchase escape from the debates he hopes to avoid. First, as David Palmer (2013, 559 - 560) points out, Capes's criticism may entirely miss its target, since the expectation central to the W-Defense need not constitute blame. Rather, the idea is that, typically, when an individual $S$ 's expectation that an agent $U \varphi$ is not met, $S$ blames $U$ for failing to $\varphi .{ }^{8}$ As Palmer notes, it is difficult to understand how such an expectation is not doing any work where blaming occurs. ${ }^{9}$ If that's correct, then, Capes's recapitulating blame as constitutively tied to a belief-desire pair as a way of withstanding

\footnotetext{
${ }^{7}$ Capes $(2010,13-15)$.

${ }^{8}$ Cf. Wallace $(1994,21-33)$ for a now classic statement of this position.

${ }^{9}$ Palmer $(2013,559-560)$.
} 
the W-Defense is a nonstarter.

Second, even if we grant Capes his claim that the W-Defense only works if expectations of a certain sort are constitutively linked to blame and allow that claim to play the role in Capes's refutation that he seems to want it to play, Capes's refutation fails because we can reformulate the W-Defense with the Humean Construal in place. Though it is true that the original W-Defense is formulated in terms of expectations about what individuals should or should not do or have done, it doesn't rely on any particular account of the nature of blame itself to go through. Indeed, the force of the W-Defense remains so long as we, like Humeans, take it that blame can be (un)reasonable, (not) fitting, or (in)appropriate. Widerker certainly frames the worry in terms of expectations - the idea is that where the expectation that disposes one to blame is unreasonable, any blame manifested by triggering that disposition is unreasonable as well. But, we can cut out this route through expectations to get to the point. That is, proponents of the W-Defense can replace

W2) But to expect that $S$ not have $A$-ed would be unreasonable if $S$ could not have done otherwise than $A$.

with

H2) But it would be unreasonable to either (a) believe that $S$ is blameworthy for $A$-ing or (b) desire that $S$ not have $A$-ed if $S$ could not have done otherwise than $A$.

Hence, whether we adopt the Humean Construal or not, if we hope to salvage arguments against PAP based on FTCs we will have to defend the idea that it is reasonable or fitting or appropriate to blame Jones despite the fact that she lacks alternatives. But, if the 
Humean must defend the idea that Jones is blameworthy despite lacking alternatives, she will have to wade into the murky metaphysical waters that Capes sought to bypass. Thus, the Humean Construal moves us no closer to undermining the W-Defense than any other acceptable account of blame's nature on which blame can be (un)reasonable, (not) fitting, or (in)appropriate. Therefore, Capes's argument fails to motivate The Humean Construal.

\section{2: $\quad$ The Humean Construal and Reactive Attitudes}

Recall that Sher (2006) argues that the Humean Construal offers a better account of blame than the Strawson-inspired Reactive Attitudes Account. Sher considers the Reactive Attitudes Account to be the most viable alternative to the Humean Construal. On his view, its excellence lies in the fact that (a) it is focused primarily on the attitudes involved, (b) it does not commit us to the idea that states like blame only involve cognitive attitudes, and (c) it accommodates the fact that states like blame play an important role in our emotional lives. ${ }^{10}$ Sher's main concern, however, is that by positing conative-affective attitudes as the only attitudes constitutively tied to blame, proponents of the Reactive Attitudes Account cannot make sense of cases of blame that involve no affect like the following:

We may, for example, feel no hostility toward the loved one whom we blame for failing to tell a sensitive acquaintance a hard truth, the criminal whom we blame for a burglary we read about in the newspaper, or the historical figure whom we blame for the misdeeds he performed long ago. As the latter examples suggest, blaming is something that we can do regretfully or dispassionately and that need

\footnotetext{
${ }^{10}$ Sher (2006, pp. $\left.71-88\right)$.
} 
not be accompanied by any rancor or withdrawal of good will. At least offhand, it seems perfectly consistent to suppose, first, that the stance I take toward my daughter for shading the truth about how much of her homework she has done is genuine blame, but, second, that that stance involves no modification at all "of the general demand that another should, if possible, be spared suffering". (Sher, 2006, $88)^{11}$

Sher introduces the Humean Construal, then, to supplant the Reactive Attitudes Account. Since belief-desire pairs are not essentially affective, Sher argues that, the Humean Construal does as well as the Strawsonian account on all other grounds and makes better sense of cases of affectless blame. Thus, he concludes that we should adopt the Humean Construal.

This attempt to motivate the Humean Construal also fails. Simply put, Sher overlooks the resources available to Strawsonians. By rejecting the Humean idea that cognitive states cannot motivate absent aid from independent desire, we can generalize the Strawsonian account and avoid Sher's criticisms. For instance, consider the following anti-Humean alternative:

Recognition Account: A moral-responsibility response is constituted by an individual $S$ 's recognition that an individual $U$ manifested a particular quality of will where (absent interference) that recognition motivates a change in (or reinforcement of) some of $S$ 's corresponding dispositions. $^{12}$

The Recognition Account is just an anti-Humean generalization of the Reactive Attitudes Account. The reactive attitudes central to the Strawsonian view primarily fulfill two

\footnotetext{
${ }^{11}$ Some deny the phenomenon like Wertheimer (1998). Others like Wallace (1994, 75 - 78) distinguish between blame and holding responsible. Cf. Wolf $(2011,344)$ and McKenna $(2012,24-26,33$ \& 106).

${ }^{12}$ Cf. Scanlon, (2008, Chpt. 4, esp. 127 - 138) and Thompson (unpublished manuscripts (a) and (b).
} 
functions relevant to responding to morally relevant attitudes and behavior. First, they recognize the quality of an agent's manifested will. And, second, as Elisa Hurley \& Coleen Macnamara (2010) point out, they do what an emotion typically does-namely, they motivate modifications in the blamer's "patterns of salience, tendencies of interpretation, and motivational profile" (384). ${ }^{13}$ The Recognition Account simply characterizes states other than the reactive emotions as blame in virtue of the fact that these other states fulfill those functions as well but are not essentially emotional or felt. Hence, the anti-Humean alternative makes sense of affectless blame while retaining the excellence of the Reactive Attitudes Account by generalizing it rather than supplanting it.

The Recognition Account may not withstand all criticism, but it is a good place holder insofar as it does at least as good as the Reactive Attitudes Account in terms of meeting Sher's conditions on an adequate account of blame. This anti-Humean alternative is a unified account of moral-responsibility responses that accommodates the idea that both affectfull and affectless responses to wrongdoing or bad character traits are properly considered instances of blame. Thus, it captures the importance that blame plays in our emotional lives while making sense of affectless blame. Hence, by Sher's initial lights, it is a viable alternative to the Reactive Attitudes Account and the Humean Construal.

Of course, the main cost of adopting an anti-Humean alternative is rejecting the popular Humean idea that without independent desire cognitive states are inert. So, though we've seen that Sher's argument is incomplete, we need further reason to think that the cost of rejecting the Humean idea is a reasonable cost to bear. In what follows, I

\footnotetext{
${ }^{13}$ To be clear, this 'first' and 'second' is not meant to identify an order in time.
} 
argue that it is. I begin by delineating common objections to the Anti-Humean Theory of Moral Motivation (AHTM) and some responses to them. I follow up by demonstrating the way in which the Humean Construal distorts the phenomenon it seeks to capture.

\section{3: Typical Objections to the Anti-Humean Theory of Moral Motivation}

As a preview, the primary worries are as follows: (a) AHTM requires some psychological states to have multiple and incompatible 'directions of fit,,${ }^{14}$ (b) There are cases in which belief-like states survive the absence of the desire to do as the belief-like state prescribes, ${ }^{15}$ and (c) AHTM's appeal to dual natured psychological states is simply ad hoc. ${ }^{16}$ Each concern is meant to show that the states posited by anti-Humeans are either incoherent or unnecessary. By way of diagnosing the incoherency, the conclusion that anti-Humean states are incoherent is taken to support the view that "belief and desire are modally distinct mental states with different natures" (Barry, 2004, 197). Thus, HTM proponents conclude, in order to motivate, a cognitive attitude must combine with an independent desire. ${ }^{17}$ I answer (a) - (c) on behalf and in favor of AHTM.

First, in support of (a), Humeans hold that attitudes only have one 'direction of fit'. ${ }^{18}$ More precisely, the idea is that cognitive attitudes have a world-to-mind direction of fit whereas non-cognitive attitudes have a mind-to-world direction of fit. In other words, roughly, belief-like attitudes respond to the world in an attempt to match the mind to the world whereas desire-like attitudes push their bearers to get the world to match

\footnotetext{
${ }^{14}$ See, e.g., Smith $(1987 ; 1994,111-119)$.

${ }^{15}$ See, e.g., Smith (1987; 1994, $\left.119-125\right)$.

16 Shafer-Landau (2003, 173 n. 11).

${ }^{17}$ More on what this independence comes to below.

${ }^{18}$ Smith (1987; 1994, 111 - 119). Many attribute directions-of-fit talk to Anscombe (1957).
} 
their desires. The Humean objects that the attitudes posited by anti-Humeans are incoherent insofar as they both strive to match their content to the world and push those who possess them to make the world match that content. Michael Smith writes:

Though it may sound like a coherent possibility that there should be such a state, it really isn't [...] A state with both directions of fit would [...] have to be such that both, in the presence of [a perception that not $p$ ] it tends to go out of existence, and, in the presence of such a perception it tends to endure, disposing the subject to bring it about that $\mathrm{p}$. Taken quite literally, then, the idea that there may be a state with both directions of fit is just plain incoherent. (Smith, 1987, 56, his emphasis)

Smith concludes that "what Humeans must deny and do deny is simply that agents who are in belief-like states and desire-like states are ever in a single, unitary, kind of state" (Smith, 1994, 119).

The main response is that the objection does not establish the conclusion. Since the belief-like portion of the state in question has a different content than the desire-like portion, it is not surprising that a single unitary state might persist absent the other. As Huw Price (1989) makes clear, this sort of argument

...overlooks the possibility that if there were a propositional attitude with alternative representations as a belief and as a desire, its content might be different in each case. Indeed its content would have to be different, for no one is suggesting that for a fixed $p \operatorname{BEL}(p)$ [(i.e. a belief that $p)$ ] and $\operatorname{DES}(p)$ [(i.e. a desire that $p]$ are the same propositional attitude. The point is rather that $\operatorname{DES}(p)$ might be equivalent to some other belief - not to $\operatorname{BEL}(p)$ but to $\operatorname{BEL}(\operatorname{DES}(p))$. (Price, 1989, 120) ${ }^{19}$

\footnotetext{
${ }^{19}$ Price also rejects arguments by Lewis (1988) and Collins (1988). Lewis (1996) continues his support for HTM and Hajek \& Petit (2004) and Weintraub (2007) respond. For different sorts of responses to (a)-style objections, see, e.g., Schueler (1991), Sobel \& Copp (2001), Coleman (2008), and Alverez (2012, 66 - 71).
} 
Price goes on to show that we can make the same point in the linguistic case:

...it is quite conceivable that a speech act might have both directions of fit. Context willing, for example,

\section{I would like to hire a Dobermann}

might be both an assertion with content concerning me and a request with content concerning dog rental. Some people would no doubt deny that it could be both. They might say that it is simply ambiguous, for example. They may be right: the point is simply that they cannot settle it by appealing to direction of fit, for there is nothing in that idea that rules out the possibility that the same (unambiguous) speech act does both jobs. (Price, 1989, 121)

Price's point is that things with a dual causal-functional profile are not incoherent at all. To further illustrate, consider Matthew S. Bedke's example of something that has a dual causal-functional profile, i.e. his leather jacket. ${ }^{20}$ Bedke takes it that the jacket serves to keep him warm and simultaneously serves to keep him stylish. Therefore, that something possesses a dual causal-functional profile provides us with no good reason to think that it is incoherent or theoretically costly.

Still, Humeans attempt to push their point in another way. They object that, if AHTM is correct, then one cannot sincerely judge that she morally ought to cease eating meat and fail to be motivated to abide by that judgment. Along this vein, Humeans sometimes refer to Michael Stocker's classic tale ${ }^{21}$ :

Recently, I read a story of what might be taken as typical of one course of life. It was said of this political figure that, in his youth, he cared a lot about the suffering of people in all parts of the world and devoted himself to making their lives better.

\footnotetext{
${ }^{20}$ Bedke (unpublished manuscript).

${ }^{21}$ See, e.g., Smith $(1994,123)$ who cites R. Jay Wallace's BA thesis as inspiration.
} 
But now he concerns himself only with the lives and fortunes of his close family and friends. He remembers his past, and he knows that there is still a lot he could do to help others. But he no longer has any desire so to do. (Stocker, 1979, 741)

The idea is that this listless politician's fairly pedestrian experience should be impossible if AHTM is correct, since, if AHTM were true, listless politician would be motivated by his sincere moral judgment, but he isn't.

In response, anti-Humeans point out that the concern raised by Stocker-type cases are only troublesome if proponents of AHTM are in fact committed to the claim that S's possession of a moral judgment entails that $\mathrm{S}$ has the corresponding motivating desire to do as the judgment prescribes. But, not all anti-Humeans are so committed. ${ }^{22}$ Rather, the anti-Humean can hold that sincere moral judgment retains its ability to motivate even where it fails to do so. As Mark van Roojen (1995) makes clear, on dispositional accounts of mental states, "a state's direction of fit is its aptness for playing a certain role" (47). Thus, the motivational quality of belief-like states that possess motivational efficacy retain their ability to motivate even where that ability is not "manifested while [an individual is] both in that state, and in generally suitable conditions for the manifestation of its aptness for the role" (Ibid., footnote omitted). ${ }^{23}$ For illustration, return to Bedke's example. When in Rome, ones leather jacket may cease to be stylish because she can't drum up the right confidence to wear it proudly. But, that does not entail that it ceases to keep its wearer warm or that it lacks the ability to function as a provider of warmth and style.

\footnotetext{
${ }^{22}$ Some of Smith's targets might actually be committed to the entailment.

${ }^{23}$ See Swartzer (2014) for an alternative response that essentially shows that anti-Humeans can use cases and explanations like those offered by Humeans to make sense of irrational behavior like the one featured in Stocker's.
} 
The final concern is (c), i.e. the worry that positing unitary states that are belieflike and desire-like—namely, besires—is simply ad hoc, given what anti-Humeans allow regarding distinguishing beliefs from desires. Along these lines, Russ Schafer-Landau writes:

One might claim that evaluative beliefs can have two directions of fit, in virtue of having two contents, one aimed at describing the value attaching to some course of action, the other aimed at characterizing the end state being sought. But this seems ad hoc, at least if one is willing in all other contexts to distinguish belief from desire in terms of direction of fit. (2003, 173 n. 11)

One way for anti-Humeans to respond is to find independent reason for positing these states. For instance, Steve Swartzer (2013) argues that besires are plausibly needed to capture the nature of appetitive desires. Following Swartzer's lead, after arguing that the Humean Construal objectionably warps the nature of blame, I offer a parallel response to the objection that besires are $a d$ hoc and further nudge us toward adopting AHTM. The basic idea is that we need besires to capture blame's nature, and, so, we have independent reason to accept besires.

\section{2: $\quad$ BLAME AND INDEPENDENT DESIRE}

Having identified important points in the debate between Humeans and anti-Humeans, I now want to show that the Humean idea that cognitive states cannot motivate absent aid from independent desire distorts the nature of blame. The independent desire at the heart of the Humean Construal is best understood as an unmotivated desire. ${ }^{24}$ The thought, depicted in Figure 2.1, is that the blame-constituting desire on the Humean Construal is

\footnotetext{
${ }^{24}$ Nagel (1970, 27 - 32) and Dancy (1993, Chpts. 1 \& 2; 2000, Chpts. 2 \& 3).
} 
unmotivated by the blame-constituting judgment and that which the judgment aims to represent. $^{25}$
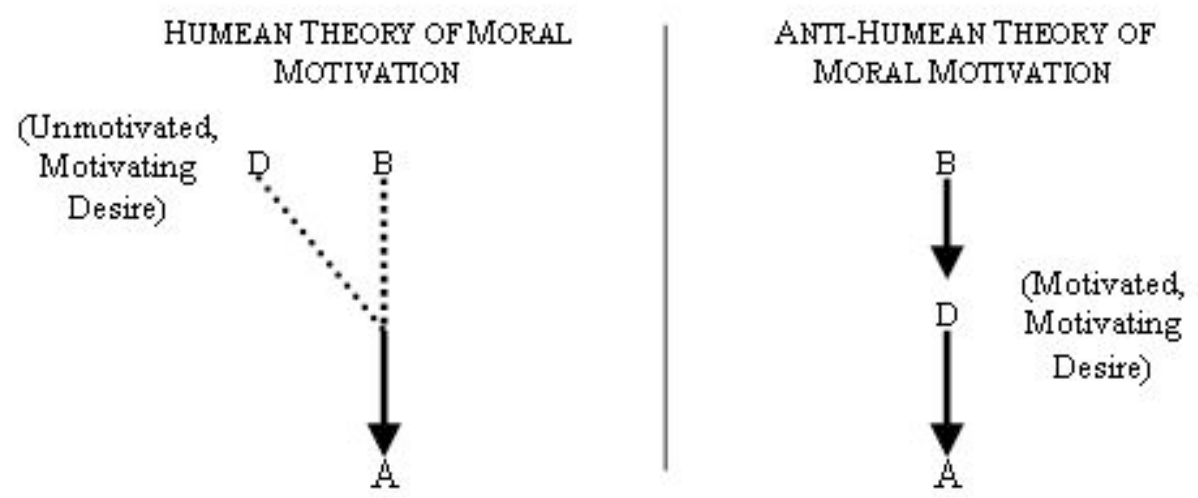

Fig. 2.1: Theories of Motivation. (B, belief; D, desire; A, motivated action or dispositional profile; dashed line, indicates non-causal relation; dark arrow, indicates causal relation.)

The Humean typically couches the independent or unmotivated nature of the motivating desire in either (a) its distinct or noncognitive origin, or (b) its prior existence. ${ }^{26}$ Upon examination, whether independence is spelled out in terms of (a) or (b) it will become clear that when a motivating desire partly constitutes blame it is best understood as motivated and (at least partly) dependent on the blame-constituting judgment. Thus, a central problem for Humeans is that they locate unmotivated, independent desire precisely where a motivated, dependent desire must reside to capture blame's nature. Therefore, we should reject accounts of blame that incorporate the Humean idea. ${ }^{27}$

\footnotetext{
${ }^{25}$ Adapted from Dancy (1993, 9, Figure 1.1).

${ }^{26}$ See Barry (2005) for a nice summary and critique of Humean commitments.

${ }^{27}$ Following Sher $(2006,112$ - 113) I'm only interested in locating the phenomenon that fulfills the causal and normative roles that moral-responsibility responses like blame do. I am not doing conceptual analysis or attempting to determine what our word 'blame' refers to.
} 


\section{1: Preliminary: Elaborating the Options}

The following will help elaborate the Humean Construal and alternatives to it:

Siblings: Hugh lives down the street from his sister, Jaclyn, who is older by roughly four years. Jaclyn has always been there for Hugh. For instance, she and her husband, Mateo, let Hugh stay with them until his transition from Indianapolis to Austin was complete. During that time Jaclyn helped him find his way around and make friends. Mateo included Hugh in his ritualistic Sunday-sports-bar afternoons and invited him to play intramural soccer. Hugh shows gratitude and does his best to reciprocate by doing things like picking up tabs and taking care of their pets. Though troubled in ways that sibling bonds often are, Hugh and Jaclyn have grown closer as a result of this late-in-life intimacy. However, their relationship is soured one Thursday afternoon. After breezing her mid-quarter review, Jaclyn excitedly heads to Hugh's condo to include her baby brother in a celebration. As she approaches Jaclyn stops. She thinks she just heard Hugh say that she is wretchedly overbearing. Jaclyn waits to hear more. As Hugh taps out his cigarette, he explains to his friend, Simone: "Jaclyn just acts like my mom and it's generally pathetic." Unable to speak or move, tears well up in Jaclyn's eyes. Her bright day slowly fades to gray. New questions about Hugh and his character sodden and reshape her interpretation of him and their latest interactions. She wonders whether Hugh had that opinion of her as they triumphantly attempted to beat Mateo at Trivial Pursuit last weekend. She stands resentful, primed to rebuke Hugh and demand an explanation.

For Humeans, Jaclyn's recognition of Hugh's spiteful words requires the aid of independent desire to motivate the corresponding change in her comportment. For proponents of the Reactive Attitudes Account, Jaclyn's recognition and the motivation priming her to rebuke Hugh is embodied in a state best characterized as an emotion. Finally, the anti-Humean can agree that Jaclyn's reaction is an emotion. Still, similar to Humeans, they hold that what makes it proper to characterize Jaclyn's reaction as a moral-responsibility response like blame is the fact that it recognizes ill will and 
motivates Jaclyn in blame-characteristic ways. But, only Strawsonians and anti-Humeans can agree that the best way to capture Jaclyn's psychology is via an appeal to a unitary motivationally efficacious complex emotion. Indeed, a significant mark against Humeans is that they must deny that anyone's, including Jaclyn's, reaction is first and foremost an emotion. Instead, they hold that blame is constitutively linked only to particular beliefdesire pairs which often motivate dispositions to be emotional.

Sher is very clear on this point. For Sher, the two types of desires that can play the requisite motivating role-i.e., (1) the desire that the person not have done what he in fact did, and (2) the desire that the person's character not be as bad as it in fact isexplain at least two things. ${ }^{28}$ They explain (i) why particular dispositions typically occur where blame occurs, and (ii) why the blamer's dispositional profile shifts when combined with the appropriate belief. ${ }^{29}$ Sher goes on to explain how these backward-oriented and present-oriented desires can motivate at all let alone motivate the blame-characteristic dispositions Sher identifies as ${ }^{30}$

(a) The disposition to be angry at the blamee;

(b) The disposition to treat the blamee in hostile ways; and

(c) The disposition to reproach the blamee.

He argues that the frustration of a blame-constituting desire leads to the disposition(s) in question. ${ }^{31}$ On Sher's view, a frustrated desire can move us to ${ }^{32}$

I. feel badly about not getting what we want; or

II. publicly express our unsatisfied desire; or

\footnotetext{
${ }^{28}$ Ibid., 102.

${ }^{29}$ Ibid., $99-101$.

${ }^{30}$ Sher $(2006,94-95)$. Sher also notes that self-blame involves the disposition to apologize.

${ }^{31}$ Ibid. $103-111$.

${ }^{32}$ Ibid. 104. The bulleted points are directly from Sher. I left out quotation marks to avoid confusion.
} 
III. substitute the pursuit of some related but more achievable goal.

Sher connects the frustration of the blame-constituting desires to dispositions (a) - (c) via (I), (II), or (III). So, for Sher, Jaclyn's disposition to be angry at Hugh is motivated by the fact that her desire that Hugh not have done what he did was frustrated. And, this frustration leads Jaclyn to take up Hugh's decision-perspective, which ends in her being disposed to be angry that Hugh did not desire to follow the moral principle which demands that persons like him show persons like her a particular modicum of respect. ${ }^{33}$

Though it is unclear where Sher thinks the phenomenon of blame ends, consistent with his departure from the Reactive Attitudes Account, blame cannot be constitutively linked to any necessarily emotional state. ${ }^{34}$ The Strawsonian, anti-Humean alternative does not share this problem, since the unitary state posited by it could be an emotion. As we'll see, its ability to mirror the states paradigmatically associated with blame renders the anti-Humean alternative theoretically superior to the Humean Construal. To further illustrate this, in the context of blame, the next two sub-sections examine the two ways Humeans understand the independence of the unmotivated, motivating desire.

\section{1: $\quad$ Independence as Distinct Origination}

According to one interpretation of independence, the blame-constituting desire is

\footnotetext{
${ }^{33}$ Ibid., 105 - 106. This goes mutatis mutandis for the other blame-constituting desire.

34 Thus, perhaps he could allow that the dispositions (a) - (c) are partly constitutive of blame. However, if the motivating frustration Sher cites is necessarily affective, it cannot be constitutively tied to blame. And, even so, it seems an individual can blame without being frustrated at all. Suppose that Jaclyn, despite maintaining a good relationship with her brother, wanted to bring some of her concerns about his lifestyle to his attention but could never find the right opportunity. In the face of Hugh's disrespect, she may see her chance. Thus, rather than being frustrated she is relieved - she finally can say what she thinks needs to be said at a moment when Hugh will likely listen. Thanks to Mark van Roojen for this point.
} 
independent of the blame-constituting belief insofar as each has distinct origins. Sher's idea is that the blame-constituting desire originates from the acceptance of moral principles whereas the blame-constituting belief originates from some epistemic reason to believe that an individual is blameworthy (e.g. perception or testimony). ${ }^{35}$

One problem here is that the agent's accepted moral principles also at least partially provide the basis for her blame-constituting judgment. If Jaclyn hadn't accepted a principle that legislates against behaving as Hugh did, it would be bizarre for her to judge that Hugh was blameworthy for doing it. And, as we saw above, even a Sher-type story about how Jaclyn comes to be disposed to resent and rebuke Hugh includes her recognizing that Hugh flouted a moral principle that she ostensibly accepts. ${ }^{36}$

Perhaps Humeans can resist this result by distinguishing between a non-rational way of originating from moral principles and a rational way. Here, the blameconstituting desire arises non-rationally from the acceptance of moral principles while the blame-constituting belief is rationally based on them.

Though this may alleviate the worry that the Humean components of blame are each tied to the blamer's accepted moral principles, it distorts the appropriateness of blame. Notice that Jaclyn's blame of Hugh seems fitting because she is reacting to what she takes to be behavior falling below her expectations. But, a commitment to the view that Jaclyn's blame is partly constituted by an independent desire where this amounts to a desire that is only non-rationally connected to Jaclyn's acceptance of certain moral

\footnotetext{
${ }^{35}$ Sher $(2006,116-133)$.

${ }^{36}$ To be clear, the worry is simply that both blame-constituting components at least in part originate from the same source - namely, the set of moral principles adopted by the blamer. This would be true even if the blame-constituting belief were about badness and not blameworthiness. I thank an anonymous referee for asking me to clarify this point.
} 
principles renders this story about Jaclyn's blame incomplete. We need to know whether the blame-constituting desire is appropriate. And, so long as the fitness of the blameconstituting desire is not somehow rationally connected to Jaclyn's moral principles, her expectations, Hugh's behavior, or some other facts on the ground, it is unclear what we should say about its (in)appropriateness. Thus, holding that the blame-constituting desire originates in a non-rational process at best leaves us committed to the view that blame's (in)appropriateness is only ever partially explicable. ${ }^{37}$

Can Humeans nevertheless rest easy with this result? I don't think so. In order to capture blame's nature at least as well as the Reactive Attitudes Account, Humeans must model it as a state that is very much like a reactive emotion. As we saw with Sher, Humeans recognize this and they see that this requires blame's representational components to be oriented toward a particular agent's act (or character).$^{38}$ The desire in question is supposed to be a representational state that partly constitutes blame not simply one that accompanies blame. Hence, as Sher makes clear, the blame-constituting desire must be about a particular agent's act or character. Part of the concern is that there are a variety of ways in which a desire can gain a certain representational orientation. Presumably, some of these ways of gaining an orientation are appropriate and others not. Without a plausible story about the way in which the blame-constituting desire arises and gains its orientation toward the individual for their act or character, we are stuck with the counterintuitive result that Jaclyn's blame is either not entirely appropriate or its appropriateness is not completely explicable. Thus, this route to maintaining a distinction

\footnotetext{
${ }^{37}$ To be clear, we're not assuming that the blamer is being irrational - she can have an attitude that is nonrationally related to another attitude or set of attitudes and still be rational. Thanks to an anonymous referee for pushing me to clarify this.

${ }^{38}$ Sher (2006, 101 - 103)
} 
in origin seems doomed to failure.

Alternatively, Humeans might suggest that unlike the blame-constituting belief, the blame-constituting desire need not originate from rational thought because that desire is simply a standing desire that one must possess in order to be rational. ${ }^{39}$ But, as we just saw, such an overarching desire that is neither tensed nor oriented to a particular past act or present character is not the blame-constituting desire of the Humean Construal.

Trouble remains even if the Humean adjusts their position to accept that the blame-constituting belief and the blame-constituting desire have distinct, rational origins. ${ }^{40}$ On this proposal, an individual can generate a desire by thinking about what she would want were she fully rational. Of course, this would involve further questions about the state's appropriateness like whether the blamer reasoned correctly about what she would want. Still, it is less objectionable than the versions just considered. At least this version allows us to effectively evaluate the propriety of an individual's blame. Furthermore, the blame-constituting desire could ostensibly have the correct orientation.

Nevertheless, this proposal is problematic. It just isn't the case that every time someone recognizes wrongdoing or a bad character she also considers what she would want were she rational and thereby generates the independent, motivating, blameconstituting desire. Jaclyn doesn't wonder what she would want were she rational. She moves from recognizing that Hugh wronged her to a new psychological orientation toward him commensurate with that recognition.

On the anti-Humean alternative the desire in question is motivated and it is

\footnotetext{
${ }^{39}$ See, e.g. Smith (1987).

${ }^{40}$ See, e.g. Smith $(1994,165)$.
} 
motivated by the recognition of wrongdoing or bad character. ${ }^{41}$ Positing that the blameconstituting desire is motivated by the blame-constituting recognition allows that each component of blame is responsive to the target of blame and that each component gains its blame-wise (in)appropriateness from the same sources. As Figure 2.2 illustrates, only the anti-Humean alternative matches the Reactive Attitudes Account on this score. And, the Humean failure is due directly to their commitment to the idea that the blameconstituting, motivating desire must be independent of the blame-constituting belief and so unmotivated by it.
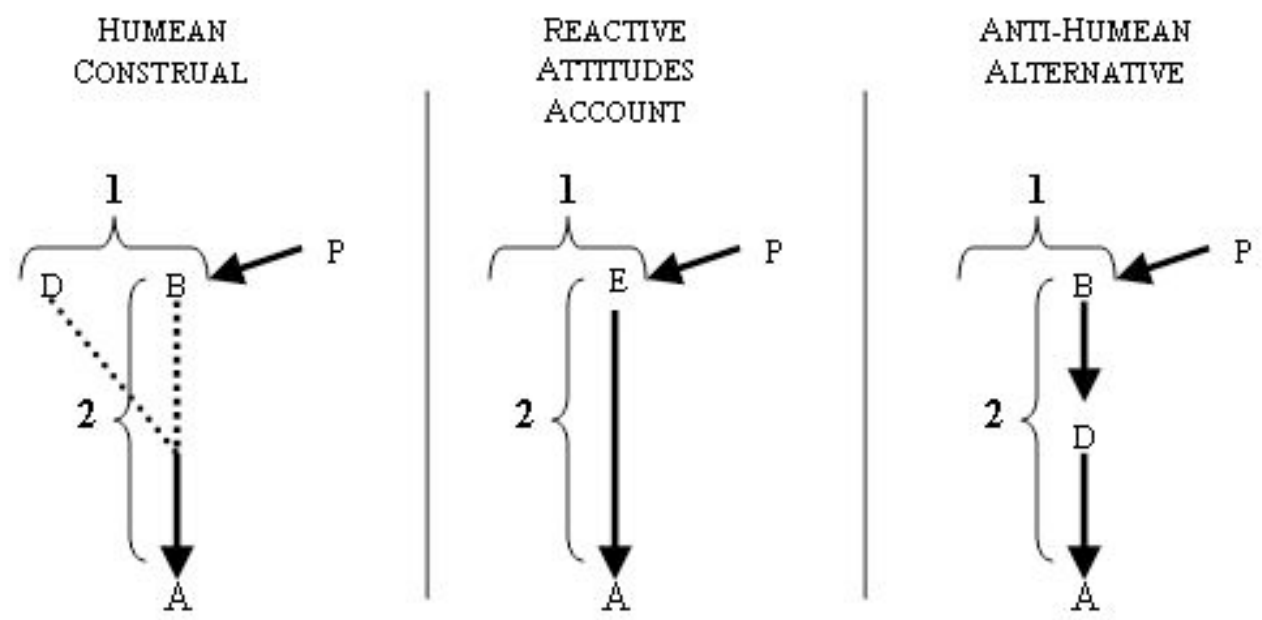

Fig. 2.2: Models of Blame: Fitness \& Origination. (B, belief; D, desire; E, complex motivationally efficacious, representational state or emotion; $P$, particular blameworthy character or act; $A$, motivated action or dispositional profile; dashed line, indicates non-causal relation; dark arrow, indicates causal relation. 1 and 2 , distinct dimensions of appropriateness; \{, the items within (except for non-causal relationships) are appropriate along identified dimension.)

To see this, return to Siblings for a moment. It appears that that which motivates a change in Jaclyn's blame-characteristic dispositional profile is appropriate and intimately connected with that to which her blame is responsive-namely, Hugh's

\footnotetext{
${ }^{41}$ I am happy to replace wrongdoing and bad character with ill or insufficiently good will and allow for a pluralist view about what an ill will amounts to as Shoemaker $(2013 ; 2015)$ does.
} 
wronging her. The Reactive Attitudes Account gets this right by positing a complex, motivationally efficacious state as wholly constitutive of Jaclyn's blame. The antiHumean alternative mirrors that account. Once we understand things like the fact that Jaclyn accepts a moral framework that counts Hugh's act as wrong and that her judgment and subsequent reaction are acceptable within that framework, we see that Jaclyn's blame is appropriate.

The Humean, however, must either (a) remain silent about the propriety of Jaclyn's blame, (b) claim that a significant portion of Jaclyn's blame is inexplicably appropriate, or (c) attribute some further bit of complex, counterfactual reasoning to Jaclyn before deciding the matter. Each of those unacceptable options result from understanding the Humean's unmotivated, independent blame-constituting desire as possessing an origin distinct from that of the blame-constituting belief.

\section{2: $\quad$ Independence as Pre-existence}

The Humean Construal fairs no better where independence is understood in terms of preexistence. On this interpretation, the blame-constituting desire exists prior to the blameconstituting belief. Here, we are to understand Jaclyn as adopting a backward-looking desire about Hugh not acting as he did prior to believing that Hugh had done something wrong. ${ }^{42}$ But, that is simply bizarre. It only makes sense for Jaclyn to desire that Hugh not have done what he did after (or as) she comes to believe that he did something wrong.

\footnotetext{
${ }^{42}$ Sher's $(2006,94$ - 111) account of how frustration of the blame-constituting desire helps motivate the blame-characteristic disposition strongly suggests that this is how he is thinking of the independence. This argument will go mutatis mutandis for the present-looking desire.
} 
Of course, Sher holds that when an individual adopts a normative principle she is thereby required to adopt certain desires that range over all times. ${ }^{43}$ But, this doesn't help. It is simply mysterious why the blame-constituting desire, which looks to the particular action for which the blamer blames the blamee, must accompany the adoption of a moral principle or the timeless desire that that principle be followed. It is mysterious primarily because that action is in the blamer's past when she blames but has yet to occur at the time the blamer adopted the relevant principle. And, again, diverging from the idea that the representational constituents of an instance of blame must each be oriented to the particular act or character that is the target of that blame is to give up any hope of accurately modeling the paradigm examples of blame central to the Reactive Attitudes Account. Figure 2.3 illustrates the difference between a version of the Humean Construal that diverges in this way from the Reactive Attitudes Account and the anti-Humean alternative. As we can see, it is striking how this divergence parts ways from our paradigmatic model of blame.

${ }^{43}$ Sher $(2006,126)$. 


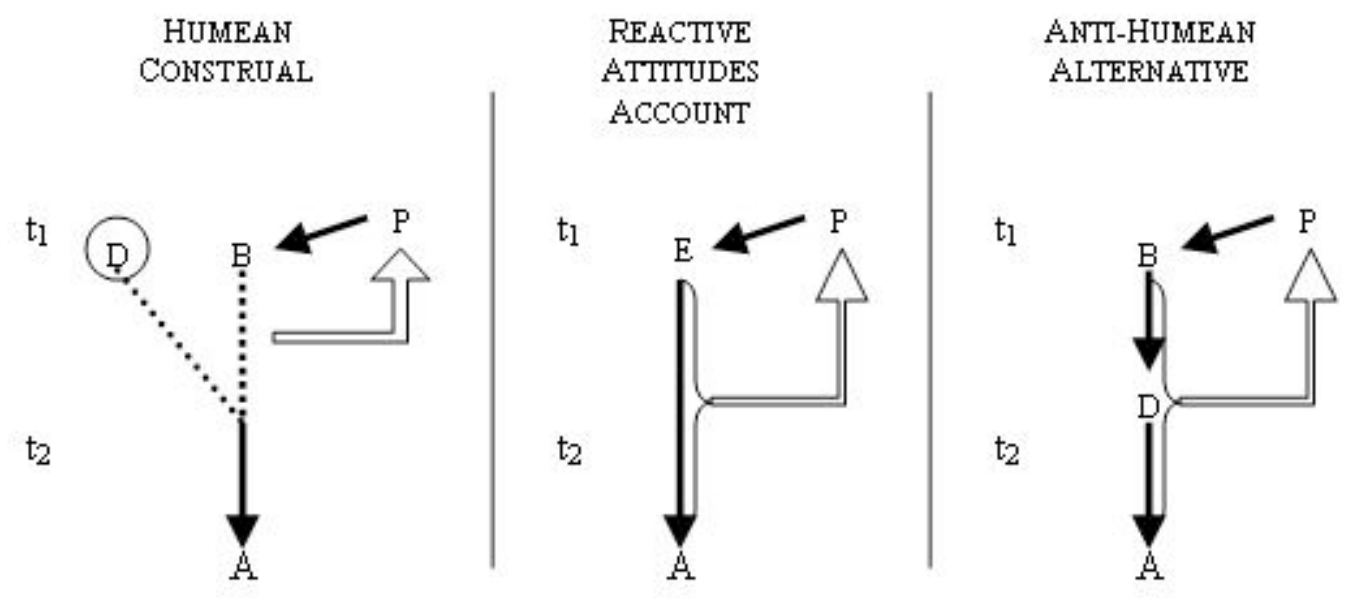

Fig. 2.3: Orientation of Components. (B, belief; D, desire; E, complex motivationally efficacious, representational state or emotion; $P$, particular blameworthy character or act; $A$, motivated action or dispositional profile; dashed line, indicates non-causal relation; dark arrow, indicates causal relation; light arrow indicates orientation; and circled component indicates that that component is not temporally oriented.)

Furthermore, whether the Humean has another way to make sense of independence as prior existence is likely to result in the same failure. The moral of the story is clear: the Humean Construal introduces independence precisely where we need blame's components to be closely linked and dependent on each other in order to capture blame's nature without distortion. Once we drop the Humean idea that cognitive states cannot motivate without the aid of independent desire, the distortions cited above disappear. On this sort of picture, whatever moves Jaclyn can arise because of, in accord with, and simultaneous to her recognition that Hugh did something wrong. This seems to best capture Jaclyn's psychology and it is a picture that only Strawonians and antiHumeans can deliver.

Further still, it is important to keep in mind that the distortions highlighted by Figure 2.2 and Figure 2.3 are significant. The Reactive Attitudes Account enjoys wide 
acceptance due to the fact that it seems to get most aspects of our responsibility responses like blame correct. Indeed, Sher's main reason for taking up a different account of blame's nature is simply that some instances of blame seem non-emotional and, by his lights, the Reactive Attitudes Account either can't make sense of such instances or can't do so very well. ${ }^{44}$ As we can see, then, it seems Sher was right to work into the Humean Construal the idea that the blame-constituting desire must be oriented toward the act or character that is the target of a particular instance of blame.

Thus, even Sher agrees that what we want is an account that very closely mirrors the Reactive Attitudes Account and does at least as good as the Humean Construal when it comes to making sense of cases of non-emotional blame. The anti-Humean alternative possesses both features. But, it also does better than the Humean Construal. The Humean must make significant departures from the models of blame central to the Strawsonian view in order to stay true to the central Humean commitment to the inertness of the cognitive. It is that commitment that forces Humeans to hold that every motivating desire is independent of and, so, not motivated by the cognitive state it joins to motivate its bearer. Thus, these commitments doom the Humean Construal to failure no matter how we understand independence. Capturing blame's nature requires that the motivating desire (where there is one) must be dependent upon and motivated by the particular recognition of ill will.

\footnotetext{
${ }^{44}$ Sher $(2006,78-91)$. For an alternative reason to reject, see, e.g. Oshana (1997).
} 


\section{3: $\quad$ CONCLUSION}

So, arguments for the Humean Construal fail. And, dropping the Humean idea that cognitive states can't motivate absent aid from independent or unmotivated desire keeps us from distorting our original understanding of blame as wholly constituted by emotion. In fact, a very significant point in favor of anti-Humean alternatives is that they can mirror the paradigmatic instances of blame central to the Strawsonian account, since it is that mirroring that allows anti-Humeans to offer elegant solutions to the non-emotional blame challenge that Sher sought to solve via the Humean Construal. Before concluding, I offer a final thought to further nudge us toward anti-Humean views of blame and ultimately AHTM (i.e. the Anti-Humean Theory of Motivation).

The nudge returns us to the final, popular objection to AHTM cited above according to which there is no good reason to posit unitary states with a cognitive and conative aspect or dual direction of fit. The nudge is grounded by Steve Swartzer's (2010) persuasive response to that objection. I argue, albeit with somewhat wavy hands, in an argument parallel to Swartzer's, that the mental states posited by the anti-Humean are no less and no more impossible, incoherent, or ad hoc than those posited by the Reactive Attitudes Account. The basic idea is that the arguments offered against the Humean Construal did not rely on a priori or a posteriori reasoning about motivation itself. Hence, if those arguments establish that we must accept that a unitary state can be cognitive and motivationally efficacious to fully account for blame's nature, AHTM can answer the objection since positing unitary states with cognitive and conative aspects is thereby independently supported. 
More precisely, Swartzer argues that a plausible hypothesis about the nature of appetitive desires, which is not motivated by a priori or a posteriori reasoning about moral motivation, is

Needy: Appetitive desire is a mode of perceptual experience of one's needs in the following sense: when an agent has an appetitive desire for $\mathrm{x}$, it seems to her (in the relevant perceptual way) as though she needs x. (Swartzer, 2013, 977, footnotes omitted).

And, Swartzer maintains that

(1) (Needy) entails that appetitive desires are besires; and

(2) (Needy) is not undermined by the standard objections to besires.

Swartzer's argument is, what I'll call, the

Appetitive Desires as Besires Argument

S1: If (1) and (2) are true, then the standard objections to besires fail.

S2: If the standard objections to besires fail, then one takes on no costs by positing besires and those who reject them must provide some other reason for denying that cognitive states can be motivational.

S3: (1) and (2) are true.

SC1: Thus, the standard objections to besires fail.

SC2: Therefore, one takes on no costs by positing besires and those who reject them must provide some other reason for denying that cognitive states can be motivational. 
My nudge toward anti-Humean construals of blame and ultimately AHTM parallels Swartzer's argument. A plausible hypothesis about the nature of moralresponsibility responses that gains support from considerations independent of the nature of motivation itself is the following anti-Humean construal of blame:

Recognition Account: A moral-responsibility response is constituted by an individual $S$ 's recognition that an individual $U$ manifested a particular quality of will where (absent interference) that recognition motivates a change in (or reinforcement of) some of $S$ 's corresponding dispositions.

Second, the following are true of the Recognition Account:

$\left(1^{*}\right) \quad$ The Recognition Account entails besires; and

(2*) The Recognition Account is not undermined by the standard objections to besires.

Given that we should not incorporate into accounts of blame's nature the Humean idea that cognitive states require the help of independent desire to motivate, $\left(1^{*}\right)$ is true. But, what of $(2 *)$ ?

$\left(2^{*}\right)$ is true as well. First, the Recognition Account is an account on which moral blame is structured by the nature of the reactive attitudes. The idea is that the reactive attitudes primarily fulfill two functions - a recognition function and a motivational function. Since the reactive attitudes are not incoherent or impossible, the states posited by the Recognition Account are not incoherent or impossible.

Furthermore, to foreclose the concern that there is some hidden incoherency without rehashing the long dialogue briefly outlined above (see $\S 1.3$ ) between those who 
reject besires and those who adopt them, I follow Swartzer in pointing out that the Recognition Account, like (Needy) is not susceptible to the concerns that promote the idea that besires are incoherent. Of (Needy), Swartzer writes:

(Needy) says that a subject's appetitive desire for $\mathrm{x}$ is really a perceptual experience as though she needs $\mathrm{x}$. This view posits besires because (i) this appearance, like other perceptual experiences, should match the world with respect to the content that it represents (i.e. the content that she needs $\mathrm{x}$ ), while (ii) this perceptual experience motivates her to satisfy the needs it represents her as having, and thus it is a state that the world is to fit with respect to the content of the purported need (i.e., with respect to $\mathrm{x}$ itself). Whatever else they may be, (i) and (ii) are clearly consistent with one another. $(2013,983)$

Likewise, the Recognition Account says that a subject's response to an individual as blameworthy for $\varphi$-ing is a state that fulfills two causal-functional roles. One function is that of recognizing an individual's quality of will. The other is motivating a commensurate change in or reinforcement of the blamer's blame-characteristic dispositional profile. The Recognition Account posits besires because ( $\left.i^{*}\right)$ these are the functions often played by sentiments that are widely believed to constitute a large portion of our responsibility responses, and (ii*) cases of affectless blame push us to model responsibility responses like blame as not essentially emotional.

This point also makes it clear that the Recognition Account is supported independently of considerations about motivation. Hence, it does more than helpfully push back against the charge of incoherence. It also reveals that we have independent reason to posit besires. Thus, it addresses the concern that positing besires is ad hoc.

Furthermore, holding that the functions noted above are central to moralresponsibility responses like blame makes sense due to at least two facts akin to Swartzer's (i) and (ii). First, blame, as is true of other recognitional states, should match 
the world with respect to the content that it represents (i.e. the content that an individual has, say, manifested a certain ill quality of will). And, second, this recognitional state can motivate the agent who recognizes that quality of will to interpret, think, or behave in accord with that recognition, and thus the response can be a state that the world is to fit with respect to the content of that recognition (and perhaps aligned with moral principles she accepts).

In conclusion, then, Jaclyn is confronted with the fact that Hugh inexcusably disrespected her. She is moved to reinterpret his behaviors, to call for justification, to rebuke him, and wait for an apology. Pealing back Jaclyn's psychology we find that her poise was not plausibly commissioned by a desire that is somehow independent of or unmotivated by the judgment that Hugh disrespected her. Rather, Jaclyn recognizes disrespectfulness and is thereby moved in accord with that recognition. Hence, considerations about the nature of blame itself move us away from the Humean idea that the cognitive requires the aid of independent desire to motivate. Given that blame is best construed as constitutively linked to motivationally efficacious recognition and not essentially emotional, we have good reason to construe blame as a psychological phenomenon involving attitudes central to AHTM. Hence, we have another reason to adopt an anti-Humean take on moral motivation.

\section{REFERENCES:}

*I'd like to thank Mark van Roojen and Steve Swartzer for extensive conversation about the topics in this paper. I thank several anonymous referees for comments on earlier drafts of this paper. I thank FranzPeter Griesmaier, Susanna Goodin, and audience members for helpful discussion at a special colloquium on my work at the University of Wyoming, December 3, 2015. I thank Aaron Elliot, Luke Elwonger, Allison Fritz, Shane George, Christopher Gibilisco, Cliff Hill, Timothy Loughrist, Chris Richards, Chelsea Richardson, Andy Spaid, Mark Selzer, Lauren Sweetland, and others in attendance at the Friday Research Colloquium at the University of Nebraska-Linocln, Fall 2015, for helpful discussion. Finally, I thank 
Derek Shiller and audience members at the $4^{\text {th }}$ Annual Philosopher's Cocoon Philosophy Conference, Fall 2016, for helpful feedback.

Alverez, Maria. 2010. Kinds of Reasons: An Essay in the Philosophy of Action. Oxford: Oxford University Press.

Anscombe, G. E. M. 1957. Intention. Oxford: Blackwell.

Barry, Melissa. 2005. 'Humean Theories of Motivation'. in Shafer-Landau, R. (ed.), Oxford Studies in Metaethics, v. 5: Oxford: Oxford University Press: $195-224$.

Bedke, Matthew. Unpublished. 'A Case for Besires'. Faculty.arts.ubc.ca/mbedke/Research.html: accessed, 1.18.14.

Capes, Justin. 2010. 'The W-Defense'. Philosophical Studies, 150/1: 61 - 77.

Coleman, Mary Clayton. 2008. 'Directions of Fit and the Humean Theory of Motivation'. Australasian Journal of Philosophy, 86/1: 127 - 138.

Collins, John. 1988. 'Belief, Desire, and Revision'. Mind, 97/387: 333 - 342.

Dancy, Jonathan. 1993. Moral Reasons. Oxford: Blackwell. 2000. Practical Reality. Oxford: Oxford University Press.

Frankfurt, Harry. 1969. 'Alternate Possibilities and Moral Responsibility'. Journal of Philosophy, 66/3: 829 -839 .

Hájek, Alan \& Pettit, Philip. 2004. 'Desire Beyond Belief'. Australasian Journal of Philosophy, 82/1: 77 92.

Hurley, Elisa \& Macnamara, Coleen. 2010. 'Beyond Belief: Toward a Theory of the Reactive Attitudes'. Philosophical Papers, 39/3: 373 - 399.

Lewis, David. 1988. 'Desire as Belief'. Mind, 97/387: 323 - 332. 1996. 'Desire as Belief II'. Mind, 105/418: 303 - 313.

McKenna, Michael. 2012. Conversation and Responsibility. Oxford: Oxford University Press.

Moya, C. \& Cuypers, S. (eds.). 2009. Philosophical Explorations, v. 14, n. 2.

Nagel, Thomas. 1970. The Possibility of Altruism. Oxford: Oxford University Press.

Oshana, Marina. 1997. 'Ascriptions of Responsibility'. American Philosophical Quarterly, 34/1: 71 - 83.

Palmer, David. 2013. 'Capes on the W-Defense'. Philosophia, 41/2: 555 - 566.

Pettit, Philip. 2001. A Theory of Freedom: From the Psychology to the Politics of Agency. Cambridge: Polity Press.

Price, Huw. 1989. 'Defending Desire-as-Belief'. Mind, 98/389: 119 - 127.

Schueler, G. F. 1991. 'Pro-Attitudes and Directions of Fit'. Mind, 100/400: 277 - 281. 
Shafer-Landau, Russ. 2003. Moral Realism: A Defense. Oxford: Clarendon Press.

Shoemaker, David. 2013. 'Qualities of Will'. Social Philosophy \& Policy, 30/1 - 2: 95 - 120. Responsibility from the Margins. Oxford: Oxford University Press.

Sher, George. 2006. In Praise of Blame. Oxford: Oxford University Press.

Smith, Michael. 1987. 'The Humean Theory of Motivation'. Mind, 96/381: 36 - 61. .1994. The Moral Problem. Oxford: Blackwell Publishing.

Sobel, David \& Copp, David. 2001. 'Against Direction of Fit Accounts of Belief and Desire'. Analysis, 61/1: $44-53$.

Stocker, Michael. 1979. 'Desiring the Bad: An Essay in Moral Psychology'. Journal of Philosophy, 76/12: $738-753$.

Strawson, P. F. 1962. 'Freedom and Resentment'. in Watson, Gary (ed.), Free Will, $2^{\text {nd }}$ edition, (2003). Oxford: Oxford University Press: $72-93$.

Swartzer, Steven. 2013. 'Appetitive Besires and the Fuss about Fit'. Philosophical Studies, 165/3: 975 988.

. 2015. 'Humean Externalism and the Argument from Depression'. Journal of Ethics and Social Philosophy, 9/2: $1-16$.

Thompson, Adam R. unpublished (a). 'Defending Promiscuous Accounts of Blame'.

. unpublished (b). 'How Anti-Humeans Keep the Blame in Blame (and Why Humeans Cannot)'.

Wallace, R. Jay. 1994. Responsibility and the Moral Sentiments. Cambridge, MA: Harvard University Press.

2011. 'Dispassionate Opprobrium: On Blame and the Reactive Sentiments'. in Wallace, R. J., Kumar, R., and Freeman, S. (eds.), Reasons and Recognition: Essays on the Philosophy of T. M. Scanlon. Oxford: Oxford University Press: 348 - 372.

Wertheimer, Roger. 1998. 'Constraining Condemning'. Ethics, 108/3: 489 - 501

Widerker, David. 2003. 'Blameworthiness and Frankfurt's Argument Against the Principle of Alternative Possibilities'. in Widerker, D. and McKena, M. (eds.), Moral Responsibility and Alternative Possibilities: Essays on the Importance of Alternative Possibilities. Burlington: Ashgate: 53 - 73.

Widerker, D. \& McKena, M. 2003. Moral Responsibility and Alternative Possibilities: Essays on the Importance of Alternative Possibilities. Burlington: Ashgate.

Weintraub, Ruth. 2007. 'Desire as Belief, Lewis Notwithstanding'. Analysis, 67/2: 116 - 122.

Wolf, Susan. 'Blame: Italian Style'. in Wallace, R. J., Kumar, R., and Freeman, S. (eds.), Reasons and Recognition: Essays on the Philosophy of T. M. Scanlon. Oxford: Oxford University Press: $332-$ 347.

van Roojen, Mark. 1995. 'Humean Motivation and Humean Rationality'. Philosophical Studies, 79/1: 37 57. 
Writing Sample 2

Adam R. Thompson 